\title{
Improving Performance of Supply Chains by Leveraged Hard Solutions and Business Cultures
}

\author{
Stanisław Strzelczak ${ }^{1}$, Haifeng Huang ${ }^{2}$ \\ 1 Warsaw University of Technology, Faculty of Production Engineering, \\ Narbutta 85, 02-524 Warsaw, Poland \\ 2 Beijing University of Technology, School of Economics and \\ Management, China Research Center for Economic Transition (CRCET), \\ 100 Pingleyuan, Chaoyang District, 100022 Beijing, P.R.China
}

\begin{abstract}
Leveraging hard solutions with business culture is an important but rarely discussed problem. The need to harmonize systems and cultures is well understood in Asia. Western researchers and managers tend to rely on reductionism and prefer to focus only those phenomena, that can be easily modeled in a quantitative manner. This paper presents initial results of an ongoing research project, which aims to develop a well-justified methodology, capable to analyze both, cultural phenomena and material processes, in supply chains. A five-dimensional hybrid model of supply chain management (SCM) practices was developed to support holistic modeling of existing or future phenomena and empirical research. The presented considerations refer to the product development and production flow processes. The obtained and expected outcomes have double, scientific and practical importance.
\end{abstract}

\section{Introduction}

The common meaning of culture as a complex whole, which includes values, beliefs, attitudes, assumptions, customs and habits, practices, rituals, taboos, ceremonies, traditions, communication patterns, archetypes (e.g. heroes and scoundrels), norms, morals and other capabilities and habits acquired by members of population applies also to the business context. In the organizational context, this definition can be extended by other items, like formalism, time-rigidness, reliability, trust, reasoning and learning patterns, decision-making patterns etc. Hatch [1] demonstrated, that a corporate culture is adopted, developed and disseminated by a company.

Cultures are dynamic. In case of individuals (managers and employees), they may be affected by many factors, which cannot be directly influenced by an organizational culture, like: gender, generation, personality, temperament, ambitions,

Please use the following format when citing this chapter:

Strzelczak, S. and Huang, H., 2008, in IFIP International Federation for Information Processing, Volume 257, Lean Business Systems and Beyond, Tomasz Koch, ed.; (Boston: Springer), pp. 403-412. 
morale, educational background, knowledge, social attitudes, religion, life experience, historical experience etc. Business cultures may be learned, adapted, shared and transmitted. They may be conflicting, harmonizing or even synergistic. Elements of culture are interrelated. Cultural integration may be supported by cultural sensitivity and deteriorated by ethnocentrism (conscious imposition of one's viewpoint) or parochialism (lack of sensitivity born of ignorance).

Johnson [2] described a cultural web, identifying a number of elements, that can be used to describe an organizational culture:

- Paradigm: what the organization is about; what it does; its mission; its values.

- Control Systems: the processes in place to monitor what is going on.

- Organizational Structure: hierarchy, reporting scheme, ways of work flow etc.

- Power Structures: who makes decisions; how widely is power spread, what is power based on?

- Symbols: logos and designs, but also symbols of power (e.g. car parking spaces)

- Rituals and Routines: management meetings, reports etc. (may become more habitual than necessary).

- Stories and Myths: build up about people and events, and convey a message about what is valued within the organization.

Recently we can observe an increasing attention paid to the organizational cultures, as important determinants for organizational success. Cultural interferences are visibly behind many stories of failing cross-border business ventures and processes. The power of cultural issues was surely enhanced by the effects of globalization. While the link between organizational culture and organizational effectiveness is still not strictly proved [3], there is no denying, that each organization has a unique social structure, and that these social structures drive much of the group and individual behavior observed in organizations. More and more authors argue, that developing a strong organizational culture is essential for success [4].

A spectacular example of corporate success rooted in organizational culture is Toyota, which for over twenty years demonstrated steady growth, outstanding business performance and superior market capitalization. Toyota does not apply peculiar materials, processes or management techniques, but its production management principles are very different from those common in USA or Western Europe. Some of them are as follows [5]:

- Base your management decisions on a long-term philosophy:, even at the expense of short-term financial goals

- Create flow to move material and information fast as well as to link processes and people together so that problems surface right away. Make flow evident throughout your organizational culture.

- Build into your culture a philosophy of stopping or slowing down to fix the problems, to enhance the productivity in the long run.

- Respect your extended network of partners and suppliers by challenging them and helping them improve. Treat them as an extension of your business.

- Become a learning organization through relentless reflection (Hansei) and continuous improvement (Kaizen).

The above statements seem to be abstract, philosophical and fuzzy, at least such is the perception by majority of Western scholars and managers, who usually love sophisticated, complex, technically faced and effortable management systems. 
Actually Toyota's principles are precise and can be reflected by exact managements practices and systems, like: safety of employment, motivation system, policy deployment practices, partnership with subcontractors etc. It is worth to note, that each of them separately cannot produce impressive results, but applied as a whole, they give amazing effects. They evidently demonstrate the importance of culture of corporation for its success. It is also worth to note, that despite a commonality of the phrase 'Toyota Production System', it actually refers to the whole supply chain.

The experience of Toyota confirms, that organizational systems and cultures are interrelated. Although this statement cannot be easily proved in a strictly scientific way, according to the Western standards, there are many examples confirming that implementing lessons from Toyota without any culture consciousness result in failures (e.g. quality circles, suggestion system, pull-flow in supply chains et. al.).

An interesting difference of Asian and Western business practices is visible in the performance assessment [6]. Asians tend to take a multifaceted view of a company, oppositely to the Western analytical, piece-by-piece assessments, by many hard indicators. Internal appraisals in Asia do not include individual assessments in the Western style, which are clear and objective, but normally deteriorate the group harmony and teamwork. When put down to the departmental or individual level, they often lead to conflicts, unfair rivalry, unneeded stress and other negative effects (in Western firms, management systems are often intentionally complicated, to prove commitment to the company or just to protect jobs).

\subsection{Existing Results}

It is visible from the literature overview, that most attempts to research cultural impacts in business, focus the national perspective and use simply patterns of analysis. Typically, few factors are considered, mostly of behavioral nature. The existing frameworks overlap, but none of them is comprehensive. They focus nations as the dominant objects, which can be attributed by different characteristics. Alternative layers of business cultures: macro- regional, regional, organizational, departmental, group cultures, subcultures and individual cultures, are usually ignored. Other business contexts than the situational (negotiations, communications), like ventures (mergers, acquisitions, supply chains, strategic alliances) and functions (advertising, motivating, accounting) are rarely reviewed [7].

It is a common view that most difficulties of SCM stem from an uncoordinated and fragmented allocation of responsibilities of the various supply chain activities to different functional areas [8]. Many publications point cross-company, cross-borders and spatial aspects of supply chains as the additional sources of difficulty. Only few recognize cultural circumstances as a major factor of supply chain performance, despite the fashion for such concepts of SCM, like the partnership, which is entirely of cultural nature [9, 10, 11]. The most common initiatives among the SCM professionals community, like the SCOR, the VCOR, or the CPFR, focus structural and procedural aspects of SCM, while the cultural considerations are totally ignored.

The existing approaches to the cultural measurement, like the OCAI (Organizational Culture Assessment Instrument) and CVF (Competing Value Framework) [12] or the Cultural Maturity Index [13], do not support joint 
performance measurement and cultural measurement. The example of Toyota puts also another question, about the trade offs between the business cultures of different levels, and the elements of hard organizational systems, like: goals, strategies, decision-making patterns, structures, performance assessment patterns, information systems, policies addressing human resources, etc.

Vanpoucke et. al. [11] targeted to assess the impact of characteristics of supply chain collaboration on performance through a questionnaire research in Western Europe. Likert scales were applied to measure all phenomena, including overall satisfaction and benefits of collaboration, and similarly, characteristics of collaboration, which were evaluated from seven perspectives: attributes of collaboration, communication behavior, supplier-customer selection process, conflict resolution techniques, systems and people. The paired-sample T-test comparisons of the most and the least successful cases were reported. No causal relations were analyzed and no trade-offs were assessed.

Aryee et. al. [10] considered inter-firm trust, power and other cultural factors of supply chain performance. The research has been limited to a literature overview and conceptual considerations. No empirical results were provided.

Van de Vijver and Vos [9] researched supply chain relations by case studies of eight Dutch companies. Supporting questionnaires were built around the following headings: culture, transparency, performance, trust, problems and problem solving, risk, and learning mechanisms. Cross-case display schemes were applied to discover patterns and similarities between the interviewees. The results were not supported by any in-depth assessments or trade-off analysis.

\subsection{Our Results}

The possibility to explore at once both, the cultural phenomena and the material aspects of supply chains performance, by the use of available quantitative data together with the qualitative information, drawn from case studies and management expertise, has been successfully confirmed. Using case studies and Delphi, we have assessed the causal relations between trust and replenishment policies. Using hybrid simulation, based on the industrial dynamics approach and the Bayesian Belief Networks (BBN), we have assessed the trade-offs between trust levels, inventory levels and stock turbulences. Finally, using management games we have assessed the trade-offs between performance measures, trust levels, inventory levels and stock turbulences. Despite a limited scope of our research and its pilot nature, some interesting conclusions can be confirmed by the gathered information:

1. In some circumstances the cultural phenomena may be more important, than the planning and control systems, to explain turbulences within supply chains.

2. Holistic consideration of culture and hard solutions is crucial, to avoid surprising inefficiencies, as well as to exploit possible, but unpredictable synergies.

3. Cultures and hard systems should be leveraged. In the supply chain context, they should be harmonized. 


\section{Methodology and Scope of the Research}

One of the few research projects, which considered simultaneously cultural and systemic aspects of industrial management with reference to the business performance, was the one led by JMNESG (Japan Multinational Enterprises Study Group). Since the beginning of the research, in mid 1980s, a fundamental viewpoint upon which all further studies were based, was defined as an 'organizational culture approach'. Using an originally developed analytical framework - the 'Six-group 23Item hybrid evaluation', the JMNESG consecutively conducted case studies supported by a limited statistical analysis. Since the start of project over 650 Japanese auto and electronics transplant worldwide [14] were reviewed. The Japanese multi-national enterprises (MNE) were being compared to the nonJapanese MNE and locals.

The Six-group 23-Item hybrid reference model reflects an ideal pattern of composition of Japanese management and production systems. Its components are presented below [Table 1]. Five-grade evaluation scale was used to assess the application or adaptation of Japanese style management. The originally developed Four-perspective evaluation method [Table 2] was used to evaluate and judge the substantive content of international transfers of management systems and technologies. The method enables to examine the degree, to which a certain system has taken root in a local community or, to which various factors composing the Japanese system have been transplanted in Japanese factories overseas. Comparisons of the situation by region, by country and by industry, or between different points of time. Typically, comparisons across the world (by macro-regions), inter-industry comparisons, comparisons of strategic typologies and extractions of common patterns and models (by regions, industries etc.) were applied during the different stages of the JMNESG research.

The research methodology of JMESG although over 20 years old, remains unique. It is one of the few, that explores in a holistic and systematic way diffusion of a particular production management system and culture. However, the objectivity of such research strongly depends on the knowledge, experience and skills of the researchers; particularly on their communication skills and good understanding of local management environments (the evaluations depend on the subjective individual assessments). Nevertheless, the JMNESG research approach has enjoyed a positive perception of international research community.

The research undertaken by authors continues those by JMNESG, but targets supply chains, not factories. The items of major importance are clustered into five dimensional hybrid evaluation reference model [Table 3]. Each item is assigned a descriptive grading scale, or - alternatively - a multiple-choice checklist (due to the limited size of this paper they are not presented). 
Table 1. The Six-group 23-item Hybrid Evaluation Reference Model

\begin{tabular}{|c|c|}
\hline Group & Items \\
\hline $\begin{array}{c}\text { Group 1 } \\
\text { Work organization and } \\
\text { administration }\end{array}$ & $\begin{array}{c}\text { Job classification (1); Multi-skilled employees (2); } \\
\text { Education and training (3); Wage system (4); Promotion (5); } \\
\text { Supervision (6) }\end{array}$ \\
\hline $\begin{array}{c}\text { Group 2 } \\
\text { Production Control }\end{array}$ & $\begin{array}{c}\text { Equipment (7); Maintenance (8); Quality control (9); Process } \\
\text { management (10) }\end{array}$ \\
\hline $\begin{array}{c}\text { Group 3 } \\
\text { Procurement }\end{array}$ & Local content (11); Suppliers (12); Methods (13) \\
\hline Group 4 & Small group activities (14); Information sharing (15); Sense \\
of unity (16)
\end{tabular}

Table 2. Four Perspective Evaluation Method

\begin{tabular}{|c|c|c|}
\hline & Human & Material \\
\hline $\begin{array}{l}\text { Methods } \\
\text { (refer to the transfer of intangible } \\
\text { elements, such as technology and } \\
\text { know-how required in building an } \\
\text { organization and implementing } \\
\text { personnel administration) }\end{array}$ & $\begin{array}{l}\text { G1 Work Organization } \\
\text { and Administration } \\
\text { All items (1-6) } \\
\text { G4 Team Sense } \\
\text { All items (14-16) } \\
\text { G5 Labor Relations } \\
\text { All items (17-20) }\end{array}$ & $\begin{array}{l}\text { G2 Production Control } \\
8 \text { (Quality Control)9 } \\
\text { (Maintenance) } \\
\text { G3 Procurement } \\
13 \text { (Methods) }\end{array}$ \\
\hline $\begin{array}{l}\text { Results } \\
\text { (concern the transfer of machinery, } \\
\text { parts and any other visible elements } \\
\text { of "ready-made" hardware, including } \\
\text { the dispatch of Japanese expatriates) }\end{array}$ & $\begin{array}{l}\text { G6 Parent-subsidiaries } \\
21 \text { (Ratio of Japanese } \\
\text { expatriates) } \\
23 \text { (Position of Local } \\
\text { Managers) } \\
\end{array}$ & $\begin{array}{c}\text { G2 Production Control } \\
7 \text { (Equipment) } \\
\text { G3 Procurement } \\
11 \text { (Local Content) } \\
12 \text { (Suppliers ) } \\
\end{array}$ \\
\hline
\end{tabular}

Seven evaluation perspectives were assumed to assess the performance of supply chains and to leverage of cultural aspects and hard solutions of supply chain management, including: profitability, productivity, capital activity, development and growth, stability and sustainability, agility / flexibility and quality. Hard (material) and soft (cultural) aspects are considered at once.

The research has been based on the inductive approach. Empirical data was used, including the expertise extracted from managers. The supply chains (i.e. the involved companies) were researched to examine interactions and correlations of cultural phenomena and material aspects. The methodological framework of the research is presented below. 
Table 3. Five-dimension Hybrid Evaluation Reference Model of SCM

\begin{tabular}{|c|l|}
\hline Dimension & \multicolumn{1}{|c|}{ Items } \\
\hline $\begin{array}{c}\text { Human Resources } \\
\text { Management }\end{array}$ & $\begin{array}{l}\text { (1) Job specialization (2) Employees development (3) Wages and } \\
\text { salaries (4) Motivations (5) Promotion (6) Supervision (7) } \\
\text { Assessments (8) Group activities }\end{array}$ \\
\hline $\begin{array}{c}\text { Operations } \\
\text { management }\end{array}$ & $\begin{array}{l}\text { (9) Process management (10) Quality management (11) Resources } \\
\text { management (12) Maintenance }\end{array}$ \\
\hline External integration & $\begin{array}{l}\text { (13) Partnering (14) Trust (15) Autonomy (16) Information sharing } \\
\text { (17) Policy deployment (18) Profit sharing (19) Customer value } \\
\text { spread (20) Responsibilities spread }\end{array}$ \\
\hline $\begin{array}{c}\text { Organizational } \\
\text { development }\end{array}$ & $\begin{array}{l}\text { (21) Operational risks management (22) Business monitoring } \\
\text { practices (23) Inter-organizational improvement activities }\end{array}$ \\
\hline Business culture & $\begin{array}{l}\text { (24) Leadership (25) Consensus role (26) Time rigidness (27) Job } \\
\text { safety (28) Formalism (29) Business values (30) Controlling (31) } \\
\text { Role of hierarchy (32) Time perspective (33) Communitarism }\end{array}$ \\
\hline
\end{tabular}

Table 4. Research Framework for Hybrid Analysis of SCM

\begin{tabular}{|c|c|c|}
\hline Step & Methods & Outcomes \\
\hline Modeling causal relations & $\begin{array}{l}\text { Field observation } \\
\text { Semi-structured interviewing } \\
\text { Cognitive pre-mapping }\end{array}$ & $\begin{array}{l}\text { Structured concepts } \\
\text { Measurement scales } \\
\text { Cause-and-effect } \\
\text { diagrams }\end{array}$ \\
\hline $\begin{array}{l}\text { Empirical evaluation of } \\
\text { impacts and trade-offs }\end{array}$ & $\begin{array}{l}\text { Limited statistical analysis } \\
\text { (Cronbach's alpha for reliability } \\
\text { and Pearson for correlations) } \\
\text { Delphi research } \\
\text { Management games } \\
\text { Bayesian-Belief Networks } \\
\text { (BBN) }\end{array}$ & $\begin{array}{l}\text { Empirically based } \\
\text { assessments of } \\
\text { correlations and } \\
\text { interdependencies } \\
\text { Influence diagrams } \\
\text { Static charcteristics }\end{array}$ \\
\hline $\begin{array}{l}\text { Exploring dynamical } \\
\text { phenomena }\end{array}$ & $\begin{array}{l}\text { Hybrid simulation (hybrid } \\
\text { algebra for symbolic and digital } \\
\text { processing) } \\
\text { Management games }\end{array}$ & Dynamic characteristics \\
\hline
\end{tabular}

The cultural phenomena and the material aspects of supply chains performance were explored at once by the use of collected quantitative data together with the qualitative information, drawn from the case studies and management expertise. Using case studies and Delphi, the causal relations between trust and replenishment policies were assessed. Using hybrid simulation, based on the industrial dynamics approach (ithink ${ }^{\circledR}$ 8.0) and the Bayesian Belief Networks (MSBN 3.0 ${ }^{\circledR}$ ), the tradeoffs between trust levels, inventory levels and stock turbulences were assessed. Finally, using management games the trade-offs between performance measures, trust levels, inventory levels and stock turbulences were assessed.

The research presented in this paper was performed during recent three years. It was done separately and/or jointly on the basis of research grants pursued by the 
Warsaw University of Technology and the Beijing University of Technology. These projects were done in twelve multi-national companies, which operate in the Central Europe and China. Demand fulfillment and product development were the two major areas of interest. The researched companies represented mostly electronic, automobile and electrical appliances sectors.

\section{Results}

The research was considered rather as a pilot. It was mainly aimed to gather a relevant experience and to develop a well-justified and reliable methodology, which could be later used for wider and more relevant empirical examinations, resulting in much better justified results. An expected practice-oriented site-effects were also welcomed, like tool-kits for management development and educational resources.

Although the research is still at an initial stage, and despite its limited scope and pilot nature, some interesting conclusions can be confirmed from the gathered information:

1. In some circumstances the cultural phenomena may be more important, than the planning and control systems, to explain turbulences within supply chains.

2. Holistic consideration of culture and hard solutions is crucial, to avoid surprising inefficiencies, as well as to exploit possible, but unpredictable synergies.

3. Cultures and hard systems should be leveraged. In the supply chain context, they should be harmonized.

Up to now we have focused a limited number of phenomena, including inefficiencies occurring within the supply chains, particularly those reflected by:

- delays (or long lead-times),

- $\quad$ shortages (or failed due dates),

- downtimes (low OEE),

- excessive stock,

- overproduction,

- oscillations and unbalanced flows,

- deteriorated quality.

The trade-offs between trust levels, inventory levels and stock turbulences were assessed and confirmed. Additionally, management games and hybrid simulations explained the trade-offs between performance measures, trust levels, inventory levels and stock turbulences in the context of different cultures.

The research incorporated practical components and extensions. An example may be the project of cultural integration done for one of the American auto-parts manufacturer operating in the Central Europe. This big globally operating company, highly integrated with many vendors and clients worldwide, has recognized that many problems at the operational level result from cultural interferences and the lack of multi-culture competencies. An example is the „bullwhip effect” in supply chains, which causes capital losses, high costs and deteriorates the competitiveness. The management of the company decided to run workshops, addressed to particular national cultures. They were focusing behavioral issues, communication patterns and 
specific business situations, e.g. decision making. Stereotypes and language problems were totally ignored. Cross-cultural management issues were also incorporated into functionally and process oriented improvement programs, e.g. in the proprietary corporate methodology addressing the collaborative product lifecycle management. The move up of supply chain was achieved through joint workshops, which involved all parties within the supply chain, supported by the external consultants. Substantial reduction of productivity and lead times was achieved. The whole program appeared to be very efficient and effective. The company later decided to extend it to all future structural ventures.

\section{Concluding remarks}

This paper briefly discussed results of research projects addressing the SCM, that jointly considered cultural phenomena and hard systems. The business impacts of multicultural environment are still poorly understood. The trade-offs between cultures and systems are not realized and the strategic potential of cultures is still commonly underestimated.

A challenging issue for the future research is the avoidance of the Heisenberg's effect, i.e. the interactions occurring between the measuring and measured, that can damage the measuring process or the measurement instruments [15]. Other problems of cross-cultural management of the global supply chains could be caused by forbidden topics, like: political correctness, taboos etc.

The following questions for the future research are still well justified:

- How to identify cultural phenomena (like habits, attitudes, values etc.)

- Systematization and structurization of concepts

- How to measure them

- How to relate casually behavioral issues to the performance effects

- How to model business impacts of behavioral phenomena, trade-offs etc.

The findings of the paper, although initial, have both, methodological and practical importance. Looking forward, the following further efforts could be continued:

- Theoretical:

○ Further structurization of concepts

- Holistic and complete evaluation methodology (including modeling tools, cause-and-effects analysis)

- Hybrid simulations of value-adding processes and cultural phenomena

- New framework for supply chain organizational design

- Empirical:

- Analyzing turbulences

- Prove, that some common (fashionable) practices result in most circumstances in deteriorated supply chain performance

- Practice oriented:

- Improvement tool-kits

- Benchmarking / IFC / Best practices

$\circ \quad$ Educational materials (management games) 


\section{References}

1. M.J. Hatch, Organization Theory: Modern, Symbolic, and Postmodern Perspectives, Oxford University Press, 1997.

2. G. Johnson, Rethinking Incrementalism, Strategic Management Journal, Vol. 9 (1988), pp. 75-91.

3. J. Kotter, Corporate Culture and Performance, Free Press; 1992.

4. S. Strzelczak, Enhancing Competitiveness by a Multicultural Business Education, International Management Review, Vol. 2 (2006) No.1, pp. 68-76.

5. J.K. Liker, The Toyota Way. 14 Management Principles from the World's Greatest Manufacturer, McGraw-Hill, 2004, pp. 35-41.

6. S. Strzelczak, Business Integration Engineering, in: Economic and Managerial Developments in Asia and Europe - Comparative Studies, edited by S.Strzelczak, Kramist Ltd., 2003, pp. 99-118.

7. S. Chanchani, A. MacGregor, A Synthesis of Cultural Studies in Accounting, Journal of Accounting Literature, Vol. 18 (1998), No.1, pp. 1-30.

8. P.-P. Dornier, R. Ernst, M. Fender, P. Kouvelis, Global Operations and Logistics, John Wiley \& Sons, 1998, pp. 216-233.

9. M. van de Vijver, B.Vos, Collaborative Relationships with Key Suppliers: An Exploratory Study of Practices in Different Industries, Proceedings of EurOMA 2006, Glasgow, 2006, pp. 1051-1059.

10. G. Aryee, R. Mason, M. Sarana, Exploring the Cultural and Trust Aspects of Business Relationships for Supply Chain Performance, Proceedings of EurOMA 2006, Glasgow, 2006, pp. 947-956.

11. E. Vanpoucke, A. Vereecke, E. Pandelaere, L. Solis, Characteristics of Supply Chain Collaboration and Their Impact on Performance, Proceedings of EurOMA 2006, Glasgow, 2006, pp. 1061-1070.

12. K. S. Cameron, R. E. Quinn, Diagnosing and Changing Organizational Culture, Prentice-Hall, 1999.

13. J. Cartwright, Cultural Transformation, Financial Times - Prentice Hall, 1999.

14. T. Abo (ed.), Hybrid Factory: The Japanese Production System in the United States, Oxford University Press, 1994, pp. 18-57.

15. S. Strzelczak, J. Strzelczak, Getting Synergy of Business Cultures in the Globalisation Era - How Asian and Western Management Cultures can Learn each from other Making Progress this Way, Proceedings of the $13^{\text {th }}$ East Asia Economic Symposium, Xi'an, 2004, pp. 124-132. 